\title{
INTERACTIONS BETWEEN PARENTING STYLE IN THE FAMILY AND THE USE OF SMARTPHONES AND TABLETS OF 2-3 YEARS OLD CHILDREN
}

\author{
Daiga Kalnina \\ University of Latvia, Latvia \\ Armands Kalnins \\ University of Latvia, Latvia
}

\begin{abstract}
The aim of the research is to identify the interactions between the parenting style in the family and the use of smartphones and tablets of 2-3 year-old children. Mixed-methods design was used for research including the use of such research methods as literature analysis, systematic literature review, questioning of parents about the parenting style, children's playing habits and usage of touchscreen devices (about 30 children 2-3 years old) and a case study (observation) about one child's usage of touchscreen devices and parenting styles. As the result of research we can conclude that children are skilful users of a smartphone and tablet when they use the device regularly, but parents do not have time to work with children, i.e. parents teach the child a skill to prevent the child from disturbing the parent. If a child has the opportunity to use a smart device on a regular basis, he or she becomes a skilled user at a level that allows a smartphone and tablet to meet their needs without the help of a parent. Parents have different views on the impact of the use of smartphones and tablets on child development (positive, negative, and unaffected). Parents whose views are dominated by the perception that the use is positive or has no effect allow children to play with the touchscreen device more often and for a longer period of time and do not impose consistent rules. The habits and skills of using smart devices for children do not have a significant relationship with the parenting style.
\end{abstract}

Keywords: Parenting styles, 2-3 year-old children, Smartphone, Tablet, Media usage habits.

\section{Introduction}

Technologies have rapidly entered our everyday life transforming the traditional ways of obtaining information, mutual communication and even the ways of children's playing. Ten years after the creation of internet the majority of adults living in the USA had at least once accessed 
the internet (Pew Internet \& American Life Project, 2000), but in 2012 already a third of the inhabitants of our planet had the access to the internet (Miniwatts Marketing Group, 2012). Since 2007 when the company Apple put iPhone in the market, mobile phones started to be used for a wide purpose and became the basis also for the development of tablets (McCarty, 2011). The research (Lynch \& Redpath, 2014) states that iPad user-friendly design creates few technical problems therefore people quickly become enthusiastic and competent users. The number of applications available in Google Play Store (before that Android Market) has increased from 16 thousand in December 2009 to 2 million and 600 thousand in December 2016. More than $60 \%$ of them are free of charge (Statista, 2016a; Statista, 2016b). The number of downloaded applications has increased from one billion in August 2010 to 65 billion in May 2016 (Statista, 2016c).

Children show interest in new technologies, especially in touchscreen devices. The senior researcher of the Paediatric department of Cork University D. Murray states that $80 \%$ of parents have touchscreen devices and 9 of 10 parents allow their small children to use them. Approximately two thirds have downloaded applications for their children (Touch-Screen Technology Usage in Toddlers, 2016). Although the majority of parents allow their children to use the touchscreen technologies they are worried about the impact of technologies on the children's development. There is a wide-spread opinion among parents that the use of technologies is harmful for the child's physical and mental health as well as that it hinders the child's development. Due to these worries, a part of parents do not allow their child to use the touchscreen devices.

The study performed in 2010 (AVG, 2011) revealed that although the majority of 2-3 years old children cannot swim (only 15\% can swim), tie the laces, prepare breakfast independently, ride the bicycle (43\% can ride), they know how to turn on the computer, to use the mouse, can play computer games and use the parents' smart phones.

Although researches are carried out in the world about the impact of technologies on the children's development, their conclusions are ambiguous: there are researches that enthusiastically support new media (incl. Galloway, 2009) and such that indicate that technologies have no place in early teaching (e.g., House, 2012). Besides, it should be taken into account that digital technologies develop very fast and thus the possibilities, way and aim of using technologies also change.

The study performed in 2004 (Alliance for Childhood, 2004) connects the use of computers with the lack of creativity in later years, obesity and even higher risk of terrorism. The authors of this article paper question the credibility of these conclusions taking into consideration how recently the computers have become accessible and common. The study from 2005 
(Miller, 2005) points out that the use of technologies should be decreased to the minimum to promote such aspects important to the child's development as playing outdoors, social interaction and cognitive interest. The study performed in 2009 (Johnson \& Christie, 2009), in turn, reveals that digital technologies serve as an educational means and is suitable in early childhood to make the child's development faster. The authors of the study claim that worries about computers repelling children from traditional activities and communication with peers have no grounds. The software adequate for the development with open-ended content can promote playing, cooperation and creative solution of problems. The authors of the study indicate that children need balance between playing in the digital and real environment.

The fact to what extent the touch screen technologies are a part of young children's life and to what extent they should be is the dilemma of today's parenting (Cocozza, 2014), taking into consideration the accessibility and use of ever increasing touch screen technologies (George, 2014). The use of touch screen technologies is perceived as a threat to what has been accepted as a "normal" (Piaget, 1972) development. Parents are often worried that children could access inappropriate content (Byron, 2008). Thus, the research problem appears which emerges in the contradiction between the parents' and children's desires as well as contradictory studies about the impact of using digital media on the child's development. The aim of the research is to identify the interactions between the parenting style in the family and the use of smartphones and tablets of 2-3 year-old children.

\section{Materials and Methods}

The sistematic literature review applying the three phase model of Joanna Briggs Institute Reviewers Manual (2014) was chosen for the data collection and processing. EBSCOhost Web search platform was used for the research basis. Articles for the analysis were selected applying the inclusion criteria (any country, the article in English, 2-3 year-old children, touch screen devices, use of the smartphone, tablet) and exclusion criteria (technologies are used for children with special needs, literature survey). Based on the analysis of articles (Price, Jewitt \& Crescenzi, 2015; Cristia \& Seidl, 2015; Ahearne, Dilworth, Rollings, Livingstone \& Murray, 2016; O’Connor \& Fotakopoulou, 2016; Nevski \& Siibak, 2016), a questionnaire was developed for parents.

The questionnaire was spread in social networks in April and May in 2016 as well as sent by e-mail toparents familiar to the research authors. 30 respondents filled in the questionnaire. 25 or $83 \%$ of respondents were mothers, the rest were fathers. The questionnaires have been filled in about 
children who are 24 to 44 months old, 22 children of them are 2 years old but 8 children are already 3 years old. 19 or $63 \%$ are boys and 11 girls. $50 \%$ of children live in Riga, $30 \%$ in another city, $10 \%$ in the countryside and $10 \%$ do not live in Latvia, i.e., they are children of Latvians who have emigrated. None of the children have eyesight problems, one child has posture problems. Parents give information about 2 children who cannot be drawn away from the digital device.

The research had also limitations. Taking into consideration the way of spreading questionnaires it was possible to reach only those parents who have access to the internet and who use social networks. The lack of the second possible way of obtaining on-line data is the respondents' unreliability because it is possible that respondents gave socially acceptable answers (Paulhus \& Vazire, 2007).

The on-line questionnaire consisted of five parts. The information about the child and the person filling in the questionnaire was obtained from the first part of the questionnaire. The second part consisted of 30 questions intended for finding out the parenting style, based on the theoretical understanding of parenting styles. The third part had 11 questions about the child's habits of using the tablet and smartphone. The fourth part allowed discovering the parents' rules and opinion about the use of tablets and smartphones by 2-3 years old children.

To describe more profoundly and to understand the use of a tablet and smartphone by 2-3 years old children, and the parents' role and to observe the introduction of the suggested recommendations and the child's actions with the touch screen devices as a result of introducing the recommendations, a case analysis was performed. The case study lasted for 6 months. A 35 months old child from the Latvian speaking family where both parents have higher education was chosen for the research. There is also an older daughter (14 years) and younger daughter ( 3 months) in the family. What the boy is able to do and willingly does with the tablet and the smartphone, what the parents' rules are and what their reaction to the child's actions is, is described at the beginning of the research. After that the observation of the child continued and the development of his skills and changes in his interests in the actions with the tablet and smartphone was fixed. 


\section{Results and Discussion}

\section{Description of the use of smartphones and tablets of 2-3 years old children}

Sometimes reading mass media, internet blogs and participating in discussions about today's children and parenting problems there emerges an impression that nowadays children choose only to play with smart devices; however, the study results show that playing with the smartphone tablet occupies only the $6^{\text {th }}$ place (mean $=4.93$ ) concerning the popularity among seven types of playing. Children most willingly choose the activities in the playground, such as swinging, sliding, playing in the sand-box (mean $=2.30$ ). The second place is taken by playing with traditional toys, e.g., dolls, cars, building blocks, and different sports activities, e.g., running, skate-boarding, ball games take the third place. This disproves the widely spread myth that the most popular way of playing for a modern child is playing with digital devices - if the child is offered a possibility to engage in traditional plays, he/she most willingly chooses them.

It can be claimed that this is a myth that today's children mainly play with digital devices and they cannot be separated from them. Thus, parents can be recommended to offer diverse possibilities of plays to their children balancing modern toys - tablets and smartphones - with traditional activities because children gladly choose such plays. If parents offer other exciting activities, then the child will not develop dependency from the virtual reality.

Playing with the tablet and smartphone is more popular among girls than boys (the mean 4.45 and 5.21, respectively). Playing with the tablet and smartphone is slightly more popular among three years old children than among 2 years old. $40 \%$ of children have started playing with a touch screen device at the age of 2, and 30\% already being one year old. $16.7 \%$ do not play with the sartphone or a tablet. One tenth has started playing with them already before turning one year old, and one child has started at the age of $3.23 \%$ of children have never played with a smartphone and $11 \%$ have never played with a tablet.

The majority of children use the smart device less than once a week. However, 8 children or $32 \%$ use the device almost every day (16\% use the smartphone every day). Approximately a third of children use the smart device less than 20 minutes a day but there are also children who are allowed to use it 1-2 hours a day.

When playing with the smartphone or a tablet, the majority of children watch cartoons. When playing with the smartphone, $28 \%$ of children play games, listen to music, $72 \%$ watch cartoons, e.g. YouTube, $88 \%$ look at photos, 32\% communicate with close people, e.g., via Skype, 
$56 \%$ take photos, $16 \%$ do other things, e.g., watch videos from folders, adjust the sound volume, keep in hands while talking with the granny on the phone, click all the symbols, try to unlock, speak with grandparents when the phone is put to the child's ear, look at the calendar or Instagram. A statistically significant medium close negative correlation $(n=-0.405)$ was observed between the child's age and watching cartoons on the smartphone, which means, that the older the child the less he uses the smartphone for watching cartoons.

When playing with the tablet, $36 \%$ of children play games, $68 \%$ watch cartoons, $16 \%$ listen to music, $10 \%$ look at photos, $20 \%$ communicate with close people, $32 \%$ take photos, $20 \%$ do other things, e.g., draw (3 children) and simply touch it because they yet cannot handle the tablet. A statistically significant medium close correlation was observed between the child's age and the use of the tablet in order to look at the photos, which means that the older the child gets the more he looks at the photos.

Children are rather skillful users of smartphones and tablets at the researched age (see Fig. 1). For example, 11 children independently start the selected game or application and 9 children choose the cartoon that interests them or another content on YouTube. It can be concluded that children have mastered fairly well simple actions that, regardless the content, are always performed in the same way, e.g., unlocking the device, adjusting the volume. Selecting the game parameters, e.g., the level of the game, heroes, etc., causes problems. This can be explained by the fact that each game has it in a different place and different game parameters are offered.

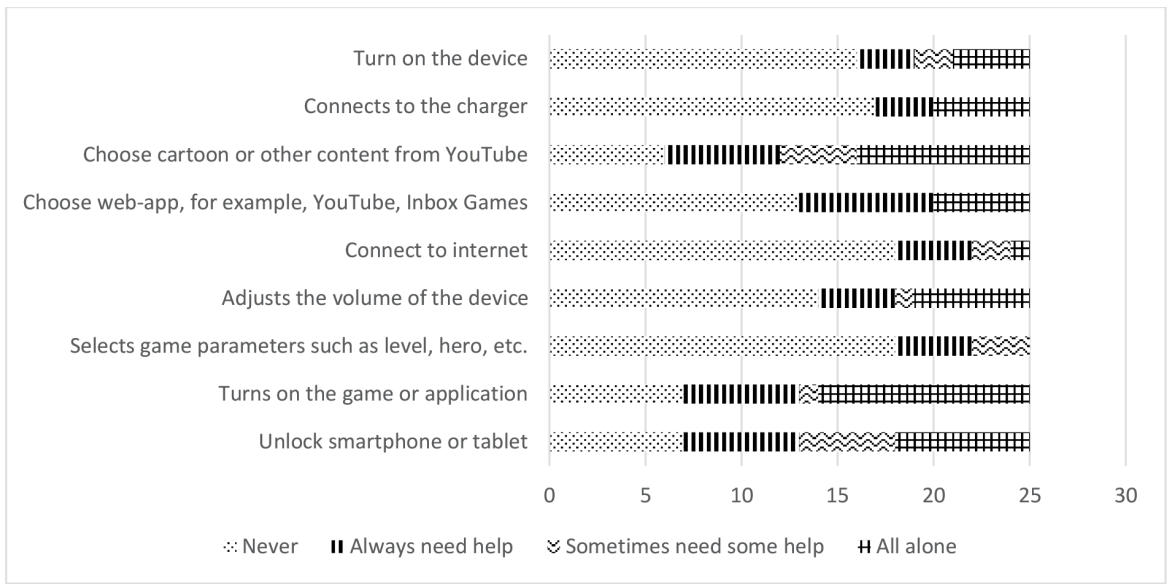

Figure 1. Skills of using the smartphone and tablet of 2-3 years old children 


\section{Parents' rules and action in regarding the 2-3 years old children's playing with the smartphone and the tablet}

Parents indicate that the majority of children (64\%) seldom have the smart device at their disposal but almost a quarter use it frequently. Comparing with the above analysed data about the children's use of tablets it can be concluded that rarely according to parents' view means 2-3 times a week or less.

The convincing majority of parents (80\%) often determine when and how much the child can play with the smartphone or tablet; yet 6 parents never do it or do it rarely. Three of the surveyed parents never state what exactly the child can do with the smartphone or tablet, e.g. which games he can play; hower, the greatest part (77\%) often do it.

Statistically significant close correlations $(n=0.769)$ were identified between how frequently parents determine what the child can or cannot do with the smart device and how long the child can play with the device. Parents who often determine what the child can do also often deterine how long the child can play with it.

These answers, similar to the study performed in 2016 in the United Kingdom (O'Connor \& Fotakopoulou, 2016), indicate that the opinion about the 'innocent child' dominates among the respondents when parents perceive children as unprotected beings who need the instructions and protection of the omniscient adult.

Although the majority of parents never use the permission to play with the smart device as an award for good work, ten parents or one third do it. Eleven parents use the smart device for punishing forbidding the child to play with it if he had been naughty. Thus, according to behaviourism theories, the possibility to play with the smart device is used both as a positive and negative reinforcement. However, parents should be careful and assess the context for the child's naughtiness so that in case of punishment the child's need for attention is not being satisfied because then unintentionally this naughtiness is being reinforced.

A statistically significant weak correlation ( $n=0.379)$ was observed between using the smartphone as an award and how often the parent determines what the child can do with the smart device - the more often it is determined the more frequently it is used as an award.

The majority or $73 \%$ of parents never change the rules and do not allow the child to play with the smartphone or tablet if the child whines or pleads but almost one fourth, although seldom, still change their rules and allow playing. Thus, the child according to the social learning theory acquire the manipulation skills and will apply them also later, e.g. when they will not want to overcome some difficulties in learning. 
$37 \%$ of parents admit that their rules about the use of the smartphone or tablet are seldom or never consistent and they are not explained to the child. Unclear borders for the child's behaviour and demands set to the child, including the use of smart devices, can promote the development of such behaviour that parents find undesirable, e.g. whining and pleading for the change of rules, manipulative actions.

Statistically significant weak correlations $(n=0.397)$ were observed between how often the parents' rules are consistent and how often the parent determines the duration of using the smart device - the more frequently the parent's rules are consistent and explained to the child, the more frequently the parent alo determines the duration of using the smart device.

Only $10 \%$ of parents have no rules and the child can play with the smartphone or tablet as he wishes and when he wishes. This can be an evidence that parents trust the child's choice and decisions or that parents are neglectful or that parents are convinced that the use of smart devices cannot harm the child.

A statistically significant medium close correlation $(n=0.571)$ was observed between how often parents have no rules for using the smart devices and how often children have access to smart devices - the more frequently the parents have no special rules and the child can play with the smart device as he wishes and when he wishes the more frequently the child has access to smart devices.

Statistically significant weak correlations $(n=0.371)$ were observed between how often parents have no rules for using smart devices and how often the parent determines what the child can do with the device - the more frequently there are no rules the more frequently the parent determines what to do. This could mean that parents according to their mood or other factors determine what the child can or cannot do during the particular time of using the smartphone or tablet. This can create confusion in children and the desire to manipulate. If clear borders and rules are not set during this age, the child might be unable to see the connection between the action and consequences and he does not develop clear and consistent habits of using devices.

Almost half of parents consider that the maximum permissibe time a day how long the child can use the smartphone or tablet is 20 minutes. One fifth of parents consider that children aged 2-3 should not use smart devices at all, and $7 \%$ of parents consider that the maximum time could be 2 hours.

Two thirds of parents use the smartphone or tablet as a nanny's substitute so that the child could give them some peace and they could rest or do some urgent chores, $13 \%$ of parents often do it. Such encouragement 
to play with smart devices can also promote the formation of the computer dependency.

Statistically significant medium close correlations $(n=0.465)$ were observed between how often the smart device is used as the nanny's substitute and how often the child has access to smart devices - the more they are used as the nanny's substitute the more accessible they are.

Assessing the impact of using the smartphone or tablet on the development of 2-3 years old children, two fifth of the surveyed parents consider that it positively affects the child's development, two fifths consider that it has a negative influence and one fifth think that it does not affect the child's development.

Statistically significant weak correlations were observed between the parents' views about the impact of using smart devices on the children's development and how often the smart devices are available $(n=0.380)$, as well as how often the parents' rules ar consistent and explained to the child ( $n=0.367$ ). Children, whose parents consider that the use of smartphones and tablets at the age of 2-3 does not affect the child's development, have access to smart devices more frequently. Rules are rarely consistent and explained to children, whose parents consider that the use of smart devices affect positively the child's development.

Thus, it can be concluded that parents' understanding of the benefits and threats of using smartphones and tablets by 2-3 years old children largely determine the parents' attitude to this way of playing. Parents who have a dominant positive view (mainly the benefits or do not see the impact on development) do not set special rules about the way or duration of using the devices. In turn, parents who have a dominant negative view (more threats to the child's development) have more rules, prohibitions and restrictions.

\section{Interrelations between parenting styles in the family and children's use of smartphones and tablets}

The parenting style in the family was determined to the surveyed parents. Authoritative style was identified for $26.7 \%$ of parents, authoritarian style for $26.7 \%$ and permissive parenting style for $46.7 \%$ of parents.

No statistically significant connections were identified in the sudy between the parents' parenting style and the child's age in which he starts playing with the smart device, how often and how long he plays with the smart device and games the child chooses to play.

A statistically significant medium close negative correlation ( $n=-0.440$ ) was observed between the parenting style and watching cartoons in the smartphone. Parents of the authoritative style allow 
watching cartoons more frequently than parents of the authoritarian style, and they more often than parents of the permissive parenting style.

A statistically significant medium close negative correlation ( $n=-0.424$ ) was observed between the parents' parenting style and the child's skill to connect the device to the charger. Children whose parents have a permissive parenting style can do it worse than children who have authoritarian or authoritative parenting style in the family.

A statistically significant medium close negative correlation ( $n=-0.410$ ) was stated between the parents' parenting style and the fact whether the parent's rules about using the smart device were consistent and explained to the child. Parents of the authoritative parenting style more often have consistent rules and explain them than parents of authoritarian or permissive parenting style.

Thus, it can be concluded that although there are observed some connections between the parents' parenting style and the habits of using smartphones and tablets by 2-3 years old children it cannot be claimed that the parenting style is the decisive factor in the formation of these habits and skills. It is rather the parents' understanding about the benefits and risks related to the use of smartphones and tablets. As only one parent of child filled the questionnaire, the author can not reject the parenting style as an insignificant factor because it is not known if the parenting style of both parents is the same and how the parents share the responsibility of bringing up children in the family regarding the rules and control over the use of tablets and smartphones.

\section{Results of the case study}

At the start of the case study it has been found that the observed boy very early (before becoming a year old) has had great interest in the computer, smartphone and tablet. Parents have to hide these devices because he wants to use them, e.g., touch the keybord of the computer, and talk on the phone. Until 15 months of age he has been shown games, i.e., the child watches how the father or older sister plays computer games and rejoice at what they see on the screen. Such activities are performed at week-ends to shorten the time, going to the countryside as well as in the evenings of week days. Having reached the age of 1 year and 3 months the child is able to coordinate the hand and finger movements and to play independently such games as My Talking Ginger, Ant Smasher; parents just have to turn on these games. The child really wants to play the tablet, he has noticed where it is kept and tries to get to it in different ways. Having got the tablet, he does not want to give it back, cries and resists. If parents do not limit the playing, he can keep playing for several hours without 
a break and laugh loudly and rejoice at what happens on the screen talking with the images of the applications, getting angry if something goes wrong. Parents have suspicion that the child has developed dependency and they refuse to give the tablet, also the older daughter and father do not play games if the boy is present. The child whines for the first week and asks for the tablet occasionally but parents do not give it. After two weeks the boy does no longer ask for the tablet and chooses himself other ways of playing and creative activities.

At the beginning of the case study (aged 37 months) the child again has increased interest in touch screen devices and he spends many hours playing with them. Parents explain that during the last months of pregnancy and then continuing to work actively and participating in social events the mother offered the smartphone as a toy to the boy thus getting time for rest or work. As the child is often ill and stays at home the mother cannot do all the intended works, therefore she gives the smartphone every day. Starting the study, the child is able to perform the following actions with the smartphone and the tablet:

- talk with the grandparents on the phone. He can stop the call pushing the red button on the screen,

- willingly and with interest he chooses and uses game applications in the tablet (he himself chooses and presses the icon of the respective game on the screen). His favourite games are My Talking Ginger, My Talking Tom, My Talking Angela, Dumb Ways to Die, Magic Piano. The main hero "talks" with the player in the first three games as well as it is possible to interact with the imge, e.g., to feed, to tickle, to brush the teeth, to wash, etc. The child especially likes to poke the image until it falls Iimitates violence) - stars that rotate around the hero's head and the changes of facial expressions cause genuine joy and laughter,

- watches cartoons and puppit films on YouTube, using the smartphone, tablet or PC. Parents have to open the internet page and find the film following the child's instructions. After watching the film in the touch screen devices, he himself chooses the next film or asks parents to find the next film in the computer. The favourite themes are cartoons and puppet films about trains (e.g., Thomas Train), films with children's songs in English (e.g., Wheels on the Bus) as well as educational films which teach colours, forms and construction of vehicles from parts,

- uses drawing programmes in the tablet. He draws with a finger, dragging lines, and chooses the function to colour larger squares and chooses completed drawings, pictograms that could be added to his work. 
The child spends 2-3 hours a day playing with touch screen devices and the PC.

Nine days after the start of the case study, the small sister arrives in the family. Mother, in order to feed the baby without hindrance, eat herself, cook dinner for the family or do other house chores, gives the boy the smartphone several times a day to watch cartoons and puppet films. Parents have accepted this kind of playing because then there is silence at home, i.e., the sleep of the little sister is not disturbed, and at the same time the boy has the possibility to be together with the mother and little sister (see a typical situation in Pict. 3.5.2). The time the child spends playing with touch screen device increases and now are 3-4 hours a day, 1-2 hours at a go. After three months the child already spends 3-6 hours playing with digital devices, watching something from 1 to 3 hours without a break at one time. The child carries the smartphone with him and watches it in any place. A small difference in the amount of using the smartphone is observed when the child is together with his father. Father is less compliant to child's demands to give him the smartphone therefore then the child uses the phone a bit less frequently.

Mother notices that the child has enlarged pupils of the eyes that do not change for a long time - only next morning they have decreased to the normal size but after 2 hours on the smartphone they gave enlarged again.

Half a year after the start of the case study the child chooses and performs the following actions which he could not do at the beginning of the case study:

- selects the YouTube icon and turns on the application,

- is able to find cartoons or puppet films of his interest,

- is able to adjust the volume of the smartphone,

- is able to connect to the charger when the notice appears on the screen that the battery is almost empty,

- uses the touch screen board in the PC using it to perform the mouse functions,

- watches cartoons and puppet films from the same theme group as at the beginning of the case study, also sings along and playing alone with toys uses phrases from the films, sometimes using words in English in his speech because does not know them in Latvian,

- plays the logic game Flow (has to connect dots of the same colour so that connecting lines do not cross),

- plays the construction game Bad Piggies (has to make the vehicle from different parts that could drive along the route) but does not perform a purposeful construction - only places together the parts and laughs loudly when the vehicle crashes, 
- opens the photo and video albums in the smartphone and watches them, turns them with a finger by himself,

- takes photos with the smartphone. Usually takes 10-15 pictures of the same object at a go.

\section{Conclusions}

The use of smartphones and tablets becomes more and more widespread among 2-3 years old children therefore parents have to be aware of the risks and benefits assessing whether and how much to allow the child to play with the touch screen device. The parenting style can influence the use of the smartphones and tablets by $2-3$ years old children but this is not the only factor influencing the use. The children's habits and skills of using smart devices have no essential connection with the parenting style; however, a trend is observed. Parents' views on the benefits and risks of using touch screen devices have a decisive role therefore it is necessary to inform and educate parents more about these issues. Parents who have a dominant view that the use of smartphones and tablets has a positive impact or no impact allow children more often and for a longer time to play with the touch screen device and do not set consistent rules.

Children are skilful users of smartphones and tablets if they use these devices regularly but prents have no time to play together with children, i.e., parents teach the child the skill so that he does not disturb them. If a 2-3 years old child has a possibility to use the smart device regularly he comes a skilful user on such a level that he could use the smartphone and tablet without the parents' help to satisfy his needs (to connect to the charger, to adjust the volume, to select the application, to choose a cartoon). Parents have to balance the time allotted to the use of touch screen devices with other activities, e.g., sports activities in the playground, playing with the toys, reading the books, creative activities, lively communication with parents and other people allowing to use the smartphone and tablet not longer than an hour a day thus decreasing the risk of developing the dependency and ensuring a diverse experience for the child's development.

The generation of children who has grown up with the smart device as a natural part of everyday life and a toy will soon start attending the school. Further studies will show the impact of the use of smart devices in early age on the child's abilities to learn. 


\section{References}

Ahearne, C., Dilworth, S., Rollings, R., Livingstone, V., Murray, D. (2016). Touchscreen technology usage in toddlers. Archives Of Disease In Childhood, 101(2), 181-183. doi:10.1136/archdischild-2015-309278.

Alliance for Childhood. (2004). Tech Tonic: Toward a New Literacy of Technology Alliance for Childhood. College Park MD.

AVG (2011). AVG Digital Skills Study. Retrieved from http://avg.typepad.com/files/avgdigital-skills-study-full-briefing.pdf.

Byron, T. (2008). Safer children in a digital world: The report of the Byron review. Nottingham: DCSF Publications. Retrieved from http://webarchive.nationalarchives. gov.uk/20130401151715/https://www.education.gov.uk/publications/eOrdering Download/DCSF-00334-2008.pdf.

Cocozza, P. (2014). Are iPads and tablets bad for young children? The Guardian, 8 January, p. 12. Retrieved from https://www.theguardian.com/society/2014/jan/08/ are-tablet-computers-bad-young-children.

Cristia, A., Seidl, A. (2015). Parental Reports on Touch Screen Use in Early Childhood. Plos ONE, 10(6), 1-20. doi:10.1371/journal.pone.0128338.

Galloway, J. (2009). Harnessing Technology for Every Child Matters and Personalised Learning, New York: David Fulton Pub.

George, N. (2014). Two thirds of UK tablet owners have an iPad. Retrieved from http:// www.t3.com/news/two-thirds-of-uk-tablet-owners-have-an-ipad.

House, R. (2012). The inappropriateness of ICT in early childhood education: Arguments from philosophy, pedagogy and developmental psychology. In: Suggate, S., Reese, E. (Eds.) Contemporary Debates in Childhood Education and Development, Routledge: New York, pp. 105-121.

The Joanna Briggs Institute. (2014). Joanna Briggs Institute Reviewers' Manual: 2014 edition. Adelaide: The Joanna Briggs Institute.

Johnson, J. E., Christie, J. F. (2009). Play and digital media. Computers in the Schools, 26(4), 284-289.

Lynch, J., Redpath, T. (2014). 'Smart' technologies in early years literacy education: A meta-narrative of paradigmatic tensions in iPad use in an Australian preparatory classroom. Journal of Early Childhood Literacy, 14(2). doi:10.1177/1468798412453150.

McCarty, B. (2011). The History of Smartphones. Retrieved from https://thenextweb. com/mobile/2011/12/06/the-history-of-the-smartphone/\#.tnw_TG63VyNt.

Media Violence Commission, International Society for Research on Aggression. Report of the Media Violence Commission. Aggressive Behavior. 2012; 38:335-341. doi: 10.1002/ ab.21443.

Miller, E. (2005). Fighting technology for toddlers. Education Digest, 71(3), 55-58.

Miniwatts Marketing Group. (2012). Internet world stats: Usage and population statistics. Retrieved from http://www.internetworldstats.com/stats.htm.

Nevski, E., Siibak, A. (2016). The Role of Parents and Parental Mediation on 0-3-Year Olds' Digital Play with Smart Devices: Estonian Parents' Attitudes and Practices. Early Years: An International Journal Of Research And Development, 36(3), 227-241. 
O'Connor, J., Fotakopoulou, O. (2016). A threat to childhood innocence or the future of learning? Parents' perspectives on the use of touch-screen technology by 0-3 year-olds in the UK. Contemporary Issues In Early Childhood, 17(2), 235-247. doi:10.1177/1463949116647290.

Paulhus, D. L., Vazire, S. (2007). The Self-report Method. In: Robins, R. W., Fraley R. C., Krueger, R. F. (Eds.), Handbook of Research Methods in Personality Psychology. New York: Guilford, pp. 224-239. http://neuron4.psych.ubc.ca/ dpaulhus/research/SDR/ downloads/CHAPTERS / 2008\%20Handbook\%20Research\%20Methods/paulhusvazire $\% 2007 \% 20$ chap.pdf.

Pew Internet \& American Life Project. (2000). Trend Data (Adults). Retrieved from http://www.pewinternet.org/Trend-Data-(Adults)/Internet-Adoption.aspx.

Piaget, J. (1972). Psychology of the Child. London: Basic Books.

Price, S., Jewitt, C., Crescenzi, L. (2015). The role of iPads in pre-school children's mark making development. Computers \& Education, 87131-141. doi:10.1016/j.compedu.2015.04.003.

Statista. (2016a). Number of available applications in the Google Play Store from December 2009 to December 2016. Retrieved from https://www.statista.com/statistics/266210/ number-of-available-applications-in-the-google-play-store/.

Statista. (2016b). Distribution of free and paid Android apps in the Google Play Store from 2009 to 2015. Retrieved from https://www.statista.com/statistics/266211/ distribution-of-free-and-paid-android-apps/.

Statista. (2016c). Cumulative number of apps downloaded from the Google Play as of May 2016 (in billions). Retrieved from https://www.statista.com/statistics/281106/ number-of-android-app-downloads-from-google-play/.

\section{Information about authors}

Daiga Kalnina - dr. paed., assistant professor of University of Latvia, Faculty of Pedagogy, Psychology and Art, member of COST Action IS1410 "The digital literacy and multimodal practices of young children" (DigiLitEY).

Armands Kalnins - master of Pedagogy, specialist in IT and security systems, researcher of digital habits of small children. 